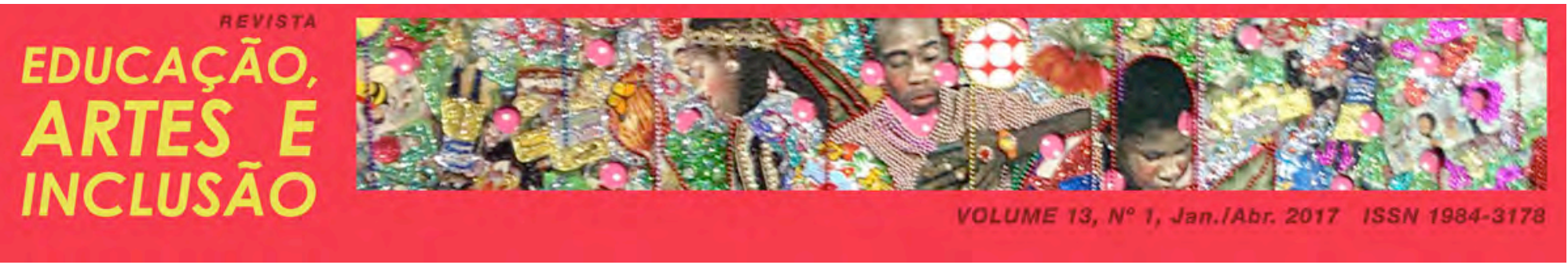

\title{
ENTREVISTA COM PAULO CESAR ALVES DE CARVALHO
}

DOI: http://dx.doi.org/10.5965/1984317813012017228

Janine Alessandra Perini - PPGAV/UDESC

Paulo Cesar Alves de Carvalho, nasceu em 1960, na cidade de Brejo, Maranhão. Atualmente mora na capital do estado e é artista plástico. Possui graduação em Licenciatura em Educação Artística e Plástica (1985) e especialização em História do Maranhão pela Universidade Federal do Maranhão (2006). Em 1998/99 fez estágio com Bolsa do MINC/Brasil no Museu Nacional do Azulejo em Lisboa, Portugal. Atualmente, é professor auxiliar do Departamento de Artes da Universidade Federal do Maranhão.

\footnotetext{
"As produções de azulejos deste consagrado artista maranhense provocam outros olhares além da contemplação, pois possuem mensagens de cunho político-social, provocam reflexão em seus admiradores, ou até mesmo, aquele telespectador que olha por pura curiosidade as figuras cotidianas, no entanto, nunca antes estas figuras foram retratadas em azulejos" (Blog Arte Açu).
}

"Paulo César (Brejo/MA, 1960), como é mais conhecido, é um artista maranhense multimídia. É performer, desenhista, cenógrafo, pintor, figurinista, escultor, ator, produtor, educador. Sua obra em variados suporte, retrato do cotidiano do homem, seus objetos de consumo, seus deleites, de valores inestimáveis; suas idas e vindas; suas angustias e desejos alcançados" (Blog Averequete).

\section{1) REAI: Comente sobre o seu processo de formação como artista.}

PAULO DE CARVALHO: Inicialmente autodidata, com atração por arte religiosa durante infância e adolescência, por ser filho de uma família votivamente católica. Nesse meio religioso estavam minhas primeiras experiências com as artes plásticas. Viemos do Piauí para São Luis em 1968, às vésperas dos meus 8 anos de idade. Minha matriz familiar é piauiense, mas nasci em Brejo, Maranhão. Foi em São Luis que aprendi a diversificar meu olhar artístico: o casario, os azulejos, a africanidade da 
população e ao mesmo tempo o tempero indígena. Logo me identifiquei. Assim, aos 123 anos da igreja de Fátima no bairro do mesmo nome, na companhia de minha mãe, comecei a me destacar nas artes e no artesanato que a igreja produzia. Depois passei a estudar na Escola Centro de Artes Japiaçu em 1974, quando fui premiado duas vezes. Logo a direção da casa me concedeu bolsa para o tempo que eu quisesse estar lá. Ali conheci os mestres Nagy Lajos (hungaro) professor de cerâmica, e Elyan (Luiz Carlos Bacelar) professor de azulejos. Essa simbiose foi perfeita para me iniciar no que mais amo fazer. A seguir veio a Universidade/ UFMA, com novos horizontes, novos paradigmas.

\section{2) REAI: Como se deu a escolha do material (azulejo) para sua expressão?}

PAUlO DE CARVALHO: Acho que respondi na pergunta anterior. Mas essa legitimação técnica se deu com a Bolsa do MinC Brasil para o estagio no Museu do azulejo em Portugal. Eu estava com 38 anos, uma experiência fascinante, pois lá tive o contato com as tecnologias antigas do fabrico desse poderoso artefato ente a Arte e a Utilidade. Fiquei um ano entre setembro de 1998 a setembro de 1999.

\section{3) REAI: Como as tecnologias influenciam seu trabalho como artista?}

PAULO DE CARVALHO: Curto muito a imagem: ver fotos, cortar imagens de jornais, revistas foi sempre uma tônica antes das mídias da computação. Hoje, as mídias da Net e da informática auxiliam muito. Assim, foi a imagem da gravura, dos tecidos estampados orientais, da mobília também oriental, informando o Ocidente nos tempos medievais e tempos modernos da renascença e do barroco. Depois veio a revolução industrial e pronto. Veio a foto, o cinema e hoje já sabemos no que deu. Mas as tecnologias da Cerâmica-Azulejar com suas diversas técnicas de produção e fabrico no passado são o âmago para a construção do meu ideário de produção, mesmo o azulejo branco, híbrido e sem graça de hoje quando usado como suporte de pintura (digo fazendo a vez da tela em branco). Esses produtos são capazes de incitar uma briga entre o artístico do século XX/XXI como atual recurso e as formas equilibradas de produção. 
Olhemos para Wandy Warol no seu Pop Art (falo de sua pujança e objetividade a partir duma foto/ mídia de então), ou para a geração dos anos 40 de artistas e arquitetos portugueses que viram na arte de azulejar de Portinary e na arquitetura de Lucio Costa um novo viés para reutilização do azulejo artístico para revestimentos de espaços públicos (tempos da construção do metrô de Lisboa), e que estavam desaparecendo mediante a ditadura de Salazar em Portugal. Assim, o Brasil fez nutrir aos donos da azulejar sua readoção nos anos 1940.

\section{4) REAI: Comente sobre o seu processo de formação como professor.}

PAULO DE CARVALHO: Fui aluno do antigo curso de Licenciatura em Desenho e Plástica, entrei na UFMA 1979, tinha 18 anos, e quando ainda era Fundação Universidade do Maranhão (FUM), creio que nesse tempo ainda era a PUC do Maranhão (Universidade Pontifícia Católica), estávamos ainda em Ditadura Militar. Deveria ter concluído o curso em 1982, mas foi quando surgiu a primeira reforma do curso, mudando o currículo e nome para Licenciatura em Educação Artística, portanto ainda fiquei 2 anos a mais para refazer a nova grade, também por conta de um período trancado, só então conclui, colando grau no dia 03 de agosto de 1985 . De fora, como artista autodidata, eu já trazia uma trilhada bagagem entre o desenho artístico e a modelagem escultórica, entre o gesso e a cerâmica, e não tardaria nessa mesma bagagem somar-se-ia o advento azuleja. Ter passado antes pelo Centro de Arte Japiaçu fez toda a diferença, tendo o contato com meus professores dessa escola João Lobato, Elyan (Luiz Bacelar), e o húngaro Nagy Lajos. Os dois últimos foram meus iniciadores no azulejo e cerâmica esmaltada. Bom na década de 1990, fiz uma especialização aqui dentro do nosso curso, mas não conclui por não ter feito a monografia. Aliás eu fui o único aluno a apresentar o projeto dessa MCC sob orientação do falecido prof. William Reis. Tempos depois em 2003 entrei na Especialização História do Maranhão (UFMA), concluindo-o com MCC intitulada: Cultura Azulejar no Maranhão sob orientação de Antonia Mota do departamento de História. Voltei à Universidade como professor substituto em 1993, já dois anos depois prestando concurso e entrando no quadro. Não cresci muito na carreira, 22 anos depois apenas sou especialista. Somando a minha experiência de ter frequentado o estagio no Museu Nacional do Azulejo em Portugal 
para a Conservação de Fachadas, com bolsa Virtuose do MinC -Brasil, perfazendo um ano, entre setembro de 1998 a setembro de 1999. Enfim essa referência foi salutar para implemento das atividades de devoluta do investimento do governo brasileiro na minha formação. Assim criamos os primeiros cursos de Conservação e Restauro de azulejos de Fachada aqui no Maranhão. Lista-se: 1) Capacitação Solidaria de Ruth Cardoso no governo FHC, 6 meses de duração com parceria da SECMA/MHAM - o Museu Histórico e Artístico do Maranhão com público-alvo jovens em idade de risco moradores de palafitas da Lagoa de Jansen; 2) Conservação e Restauro de Azulejos/ parceria Gabinete do Prefeito Tadeu Palácio e Núcleo Gestor (CHSLZ)- CAJ centro de Arte Japiaçu, para técnicos da área da prefeitura de São Luis; 3) e ainda com a presença do Núcleo Gestor do Centro Histórico de São Luis abrimos o Piloto da Fundação Monumenta do IPHAN, o Curso Escola de Azulejaria com empenho de R\$300.000,00 em 2005 para 02 turmas em duas etapas, contudo houve apenas a primeira turma.

\section{5) REAI: Quais as relações entre sua prática artística e sua prática pedagógica?}

PAULO DE CARVALHO: Busco sempre uma relação direta entre o fazer artístico e a intenção do fazer. Logo assim se acha o Alvo, o Para Que... O método, portanto, busquei corrigir nas minhas práticas aquilo que foi ausente em uma parte da minha formação superior. Pois na condição de professor-artista às vezes somos muito criticados por posturas. Acredito que da forma que venho trabalhando nos últimos 16 anos, desde a minha vinda do estágio de Conservação e Restauro de Azulejos de Fachada no Museu do Azulejo em Lisboa, pois lá tive a oportunidade de melhor ver o Brasil, o Nordeste e me reorganizar como professor. Desse modo, os processos metodológicos foram fluindo e se reconectando com o fazer artístico. Nessa premissa, a contribuição da nova Lei de Diretrizes e Base, proposta ainda por Darcy Ribeiro foram um campo de fertilizantes para novas posturas acadêmicas de minha parte. Contudo, o livro "Leituras no subsolo" de Ana Mae Barbosa também veio a calhar com posições pontuais da DBAE e sua tupiniquização posta pela Proposta Triangular. 
6) REAI: Percebi em sua obra a temática indígena, em especial na obra Sandálias do Índio Galdino, 2012. Comente sobre a inserção desta temática em sua vida e obra.

PAULO DE CARVALHO: A princípio, eu estava experimentado novas formas iconográficas nos meus azulejos, meu Art Pop, principalmente a simplificação de zonas de superfícies cromáticas presentes na obra de Wandy Warrol, esse foi parte do início formal. Do outro lado, a cena do crime com o indígena me tocou, estávamos perto das comemorações dos descobrimentos (Brazis). Juntei a fome e a vontade dessa interlocução emblemática: Poética e Denúncia, a sandália tipo chinelo de dedo feito em borracha, sabe? A popular japonesa, ou a nobre marca sandália Havaiana, ou uma subversão... a pobre marca Dupé, marca mais barata, e que figurava num conteúdo formal de painel azulejar ou simplesmente um padrão avulso azulejar. Estampada em azul cobalto, prodígio do barroco joanino português, e lá estava a chinela toda corroída, carcomida à altura do calcanhar, um desgaste épico-social, onde o topo do pé pelo calcanhar não será mais o potencial de Aquiles, mas um pé vadio e sujo, sujo de lama com couro rachado e bichorento (existe essa palavra? Acabo de criar). Assim é o Brasil genocida. Objetos daqueles que são diariamente assassinados na rua. Objetos que sempre adornam a cena do crime. Desse modo, não foi indiferente a chinela estar ali na cena. Essa foi a cumplicidade da minha metodologia de metáforas criativas.

7) REAI: Em suas aulas na graduação, você aborda sobre as questões étnicoraciais? Sobre a arte e cultura afro-brasileira e indígena? Como?

PAULO DE CARVALHO: De forma direta não, nunca fiz isso. Mas faço à medida de uma consciência, quando ela é espontânea. Nesse aspecto não forjo. Acho que forçar a barra criativa entre a individualidade e a necessidade em algumas circunstâncias soa falso. A legislação é um norte, ela instrui, mas para ser respeitada precisa de mudanças de posturas internas de cada um de nós, sem esse apelo interno não-Revolução. 
8) REAI: Algumas críticas têm sido vistas de forma sistemática na inserção da Lei 11.645/2008 na escola, principalmente vindo do movimento Escola sem Partido. Que considerações você tem em relação a essas mudanças?

PAULO DE CARVALHO: Com as posturas na Contra-Reforma da Educação posta pela equipe ditadora do governo Temer, estaremos ferrados daqui pra frente. Estamos declinando com recuos nos avanços sociais, e com os reparos raciais àqueles que foram violentados na condição da escravidão para sustento eurocentrista (pela construção de fortunas aos vagabundos de pele branca), fato que gerou a exclusão negra no Brasil, negando à África e aos ameríndios brasileiros seus direitos e indenizações. E como Educadores à deriva, vamos perder campo de trabalho em nossas formações em Arte, Sociologia, Filosofia, Educação Física. E por tal entendo que uma sociedade apática é patamar de sustentação, uma tirana "monarca", e que ora se fardou de democracia.

\section{OBRAS}

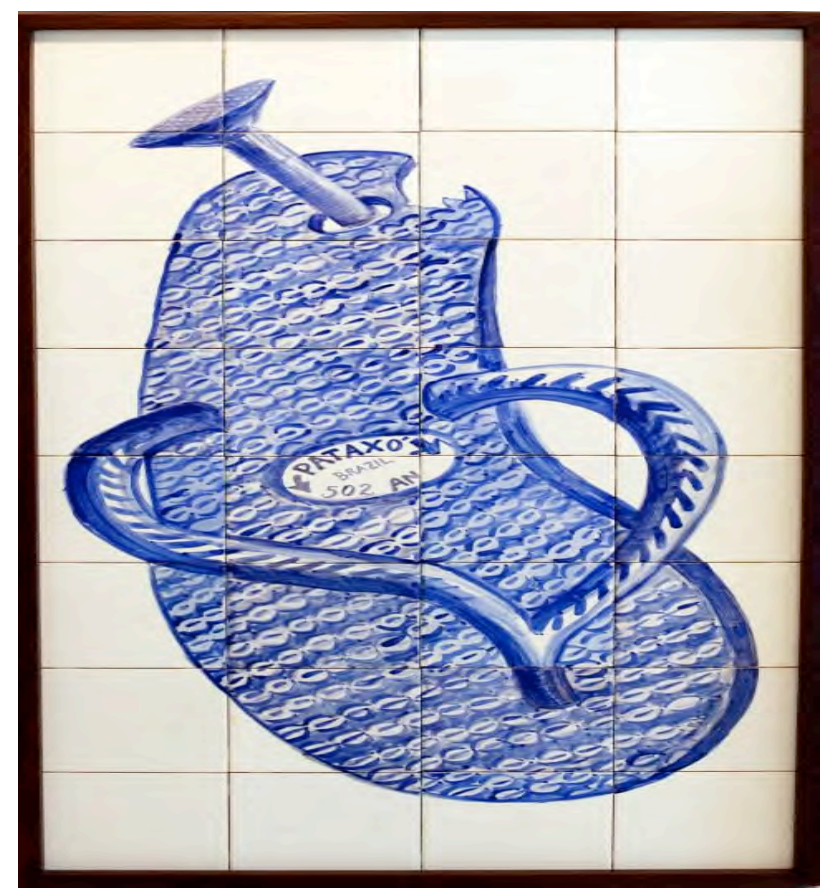

Pataxó, 2001 


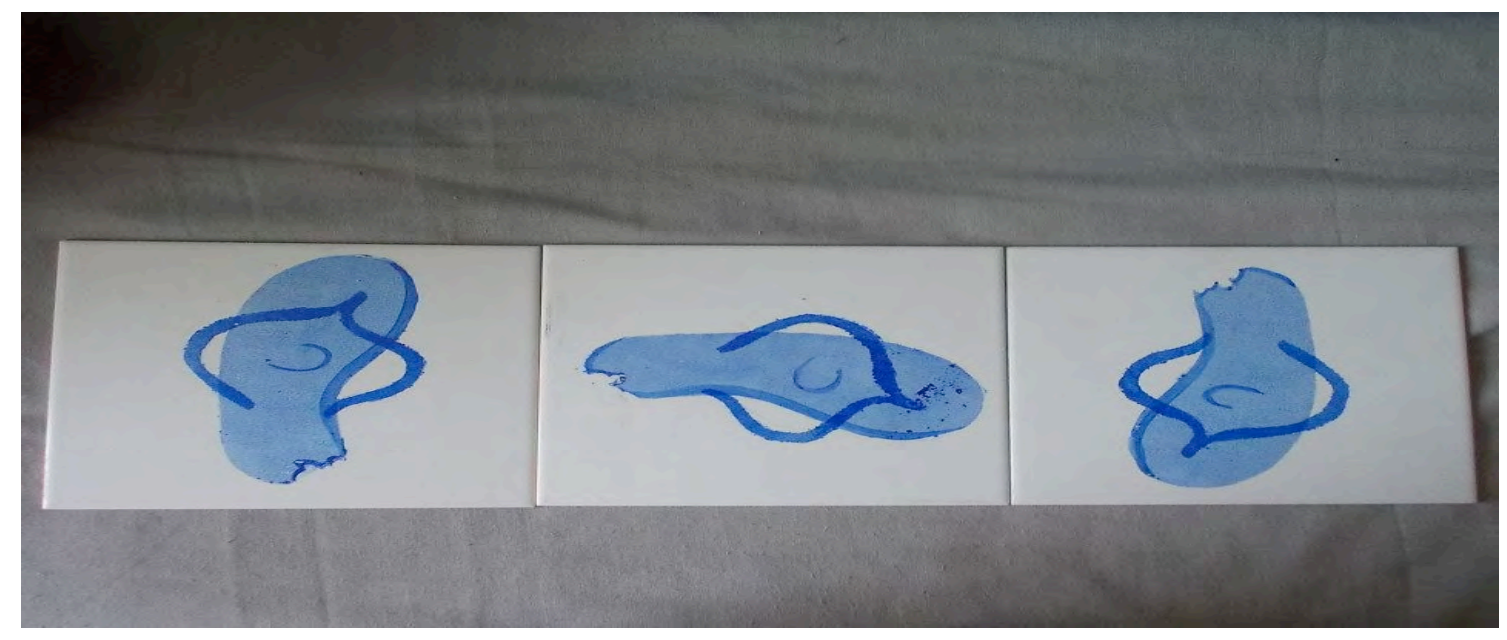

Sandálias do Índio Galdino, 2012
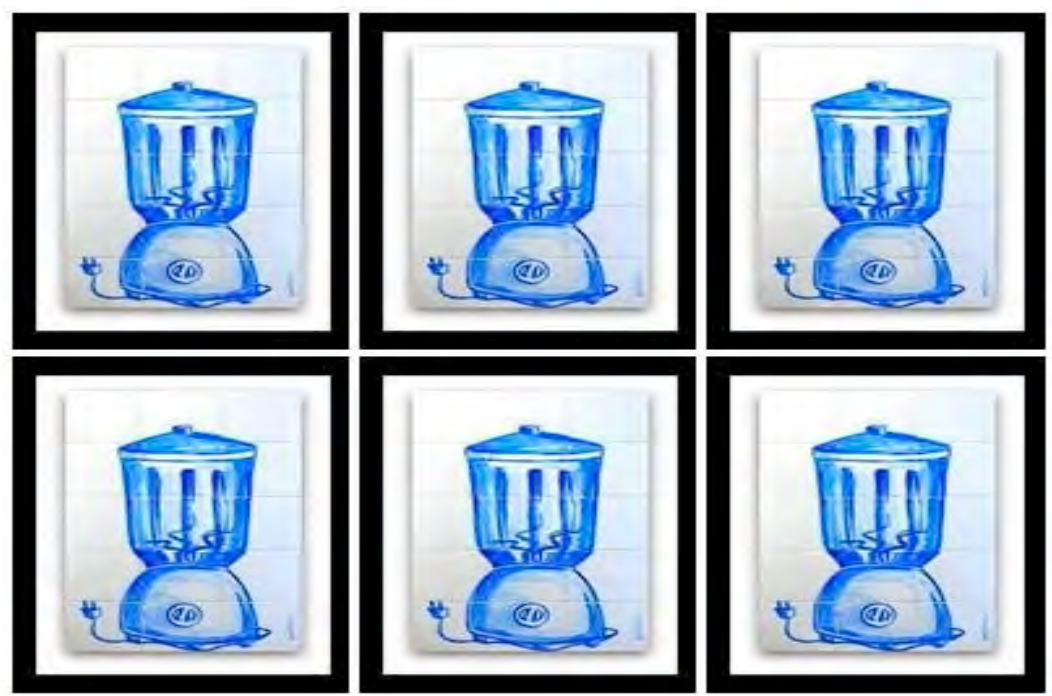

Liquidificador, 2000 


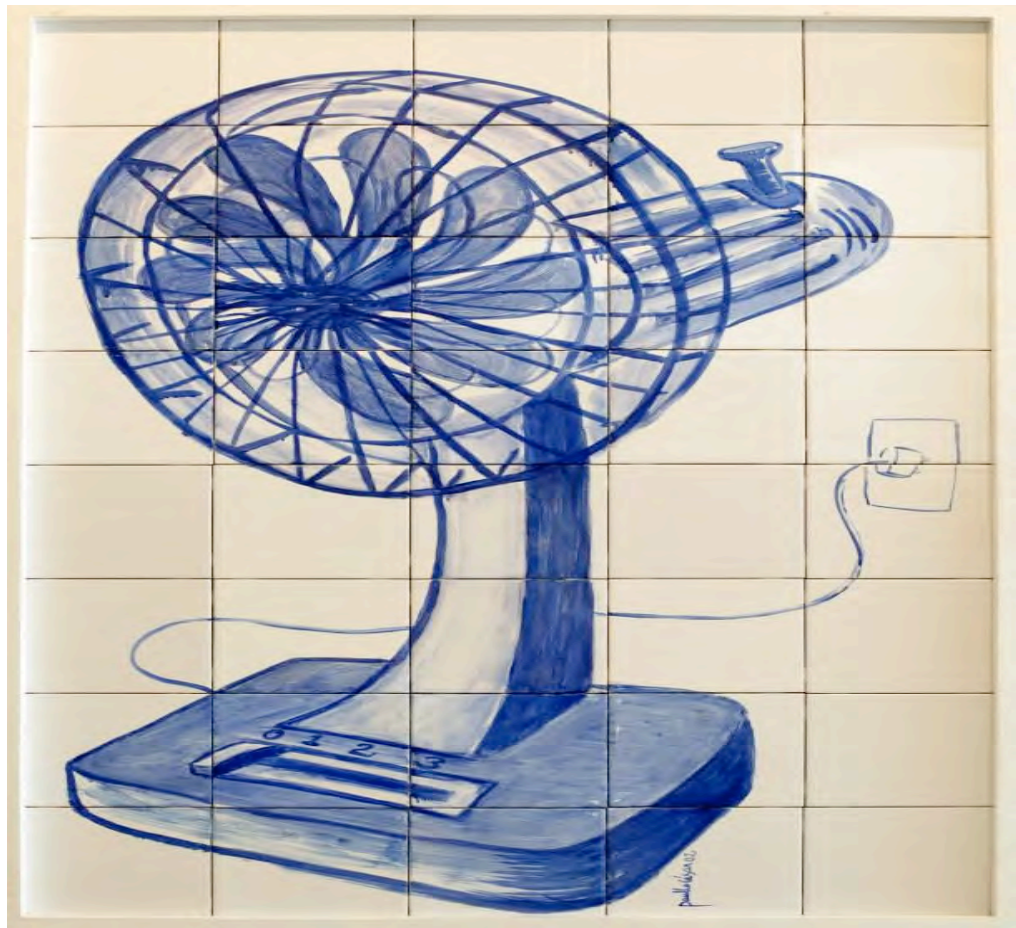

Ventilador, 2000

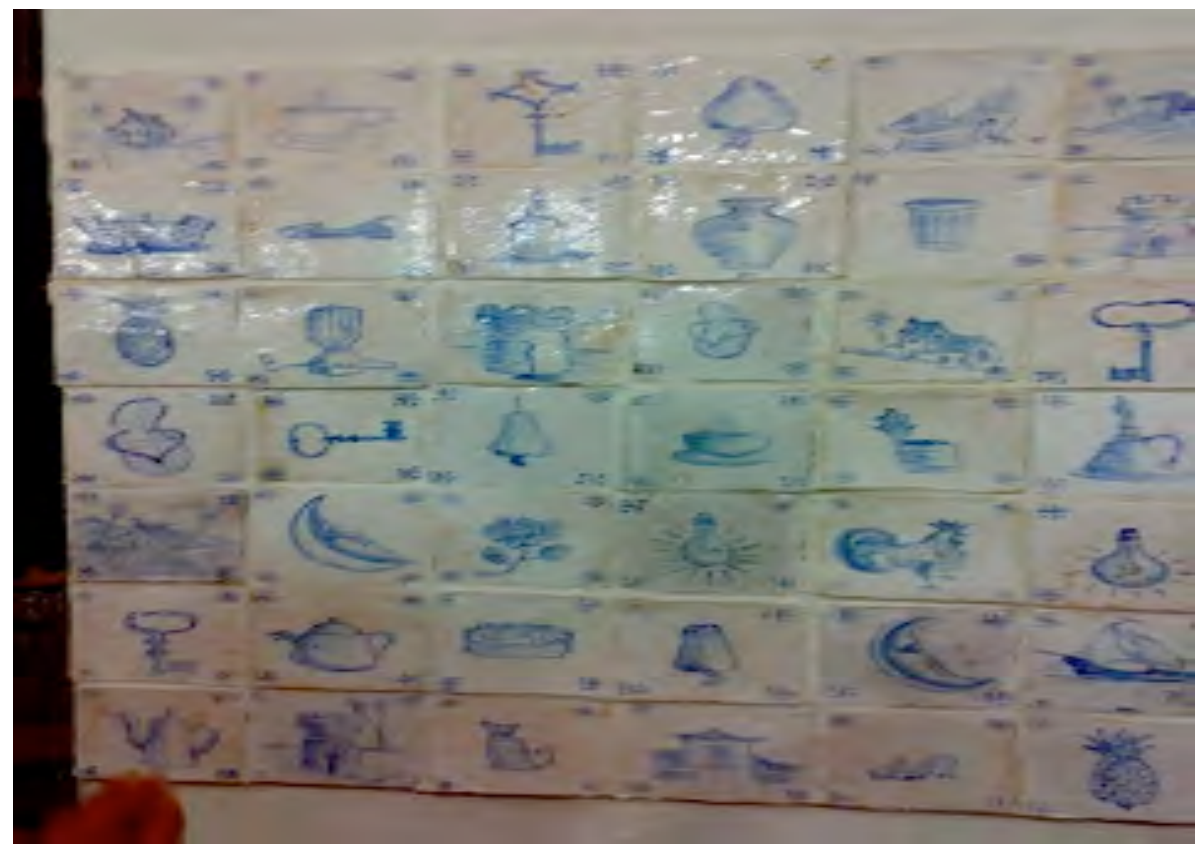

Site Specific Trapiche Santo Ângelo. São Luís/MA, 2010 

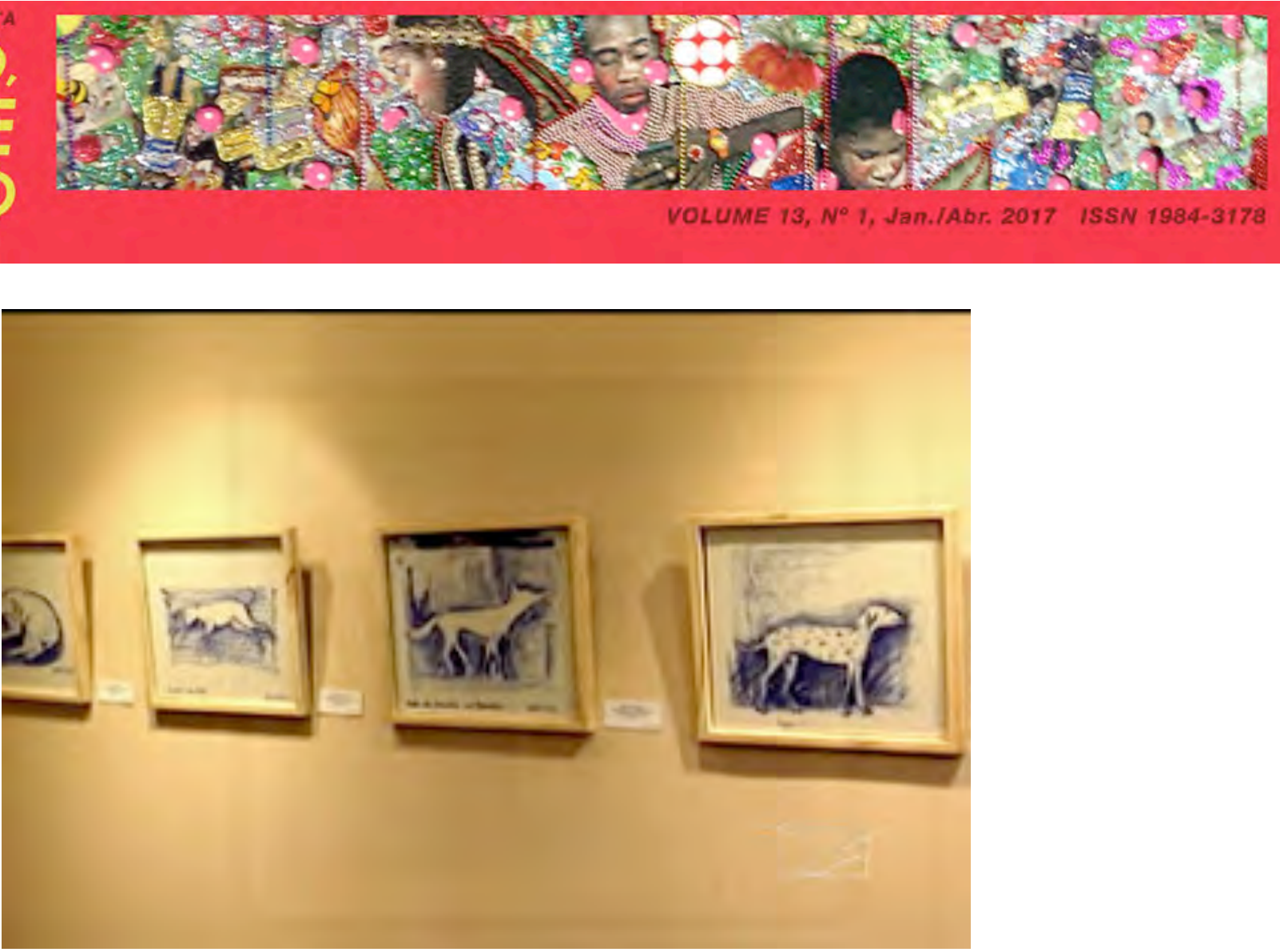

Azulejos vira latas

\section{REFERÊNCIAS}

Blog Arte Açu. Disponível em: http://arteacuifma.blogspot.com.br/2013/03/paulo-cesar-alvesde-carvaho.html. Acesso em: 21 dez. 2016.

Blog Averequete. Disponível em: http://averequete.blogspot.com.br/2013/04/paulo-cesar-alvesde-carvalho.html. Acesso em: 21 dez. 2016. 
EDUCAÇĀAOO, 4
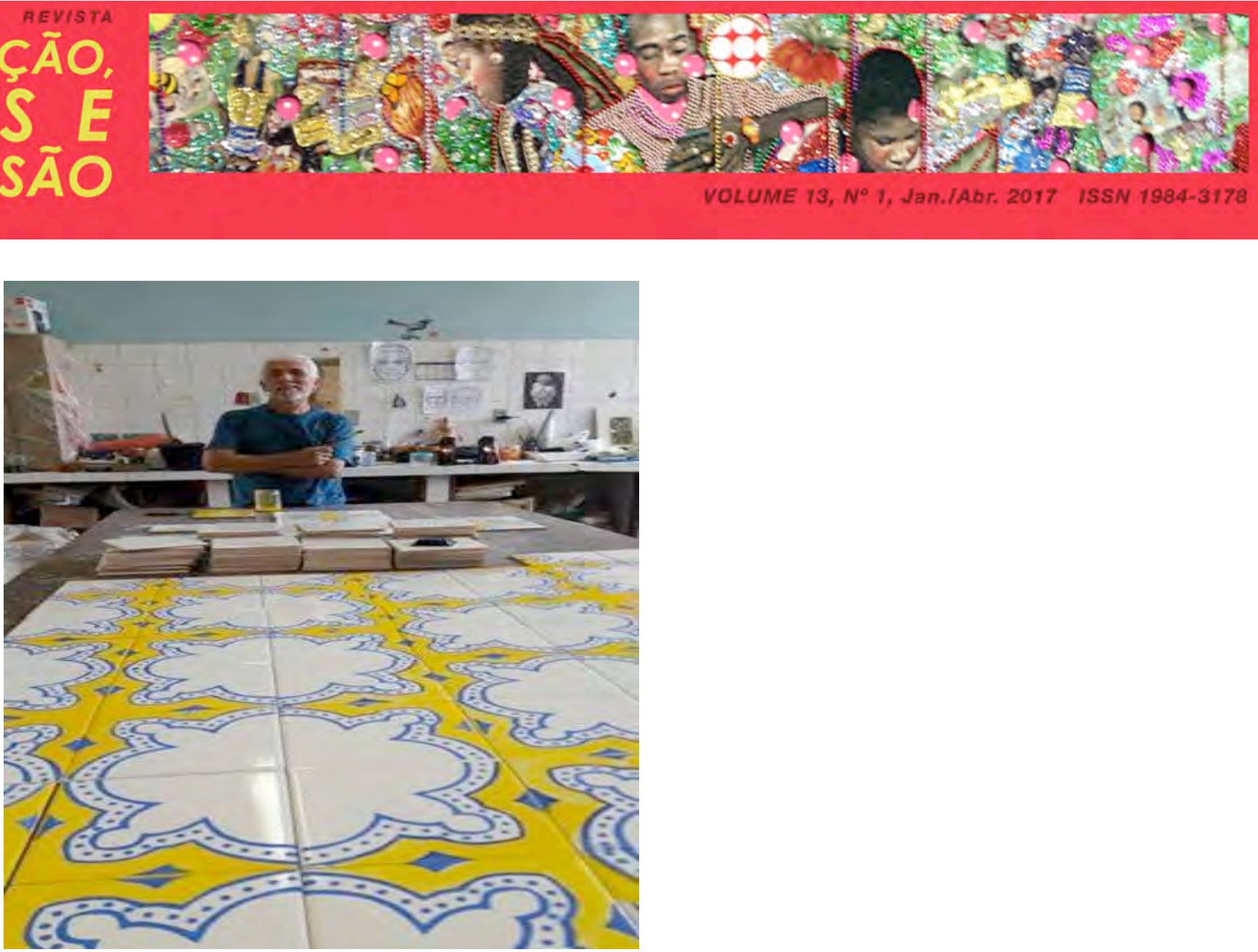

Entrevista por email com o artista Paulo Cesar Alves de Carvalho, dia 12/12/2016. 